\title{
AKATSUKI returns to Venus
}

\author{
Masato Nakamura ${ }^{1 *}$, Takeshi Imamura ${ }^{1}$, Nobuaki Ishii ${ }^{1}$, Takumi Abe ${ }^{1}$, Yasuhiro Kawakatsu', Chikako Hirose ${ }^{1}$, \\ Takehiko Satoh', Makoto Suzuki ${ }^{1}$, Munetaka Ueno ${ }^{1}$, Atsushi Yamazaki ${ }^{1}$, Naomoto Iwagami², \\ Shigeto Watanabe ${ }^{3}$, Makoto Taguchi ${ }^{4}$, Tetsuya Fukuhara ${ }^{5}$, Yukihiro Takahashi', Manabu Yamada ${ }^{7}$, \\ Masataka Imai ${ }^{6}$, Shoko Ohtsuki ${ }^{8}$, Kazunori Uemizu$^{1}$, George L. Hashimoto ${ }^{9}$, Masahiro Takagi $^{10}$, \\ Yoshihisa Matsuda ${ }^{11}$, Kazunori Ogohara ${ }^{12}$, Naoki Sato ${ }^{11}$, Yasumasa Kasaba ${ }^{13}$, Toru Kouyama ${ }^{14}$, Naru Hirata ${ }^{15}$, \\ Ryosuke Nakamura ${ }^{14}$, Yukio Yamamoto ${ }^{1}$, Takeshi Horinouchi ${ }^{16}$, Masaru Yamamoto ${ }^{17}$, Yoshi-Yuki Hayashi ${ }^{18}$, \\ Hiroki Kashimura ${ }^{19}$, Ko-ichiro Sugiyama', Takeshi Sakanoi ${ }^{13}$, Hiroki Ando', Shin-ya Murakami ${ }^{1}$, Takao M. Sato ${ }^{1}$, \\ Seiko Takagi ${ }^{20}$, Kensuke Nakajima ${ }^{21}$, Javier Peralta ${ }^{1}$, Yeon Joo Lee', Junichi Nakatsuka', Tsutomu Ichikawa', \\ Kozaburo Inoue', Tomoaki Toda', Hiroyuki Toyota', Sumitaka Tachikawa', Shinichiro Narita',

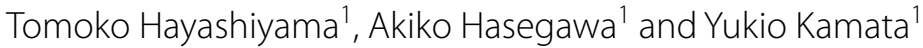

\begin{abstract}
AKATSUKI is the Japanese Venus Climate Orbiter that was designed to investigate the climate system of Venus. The orbiter was launched on May 21, 2010, and it reached Venus on December 7, 2010. Thrust was applied by the orbital maneuver engine in an attempt to put AKATSUKI into a westward equatorial orbit around Venus with a 30-h orbital period. However, this operation failed because of a malfunction in the propulsion system. After this failure, the spacecraft orbited the Sun for 5 years. On December 7, 2015, AKATSUKI once again approached Venus and the Venus orbit insertion was successful, whereby a westward equatorial orbit with apoapsis of $\sim 440,000 \mathrm{~km}$ and orbital period of 14 days was initiated. Now that AKATSUKI's long journey to Venus has ended, it will provide scientific data on the Venusian climate system for two or more years. For the purpose of both decreasing the apoapsis altitude and avoiding a long eclipse during the orbit, a trim maneuver was performed at the first periapsis. The apoapsis altitude is now $\sim 360,000 \mathrm{~km}$ with a periapsis altitude of $1000-8000 \mathrm{~km}$, and the period is 10 days and $12 \mathrm{~h}$. In this paper, we describe the details of the Venus orbit insertion-revenge 1 (VOI-R1) and the new orbit, the expected scientific information to be obtained at this orbit, and the Venus images captured by the onboard 1- $\mu \mathrm{m}$ infrared camera, ultraviolet imager, and long-wave infrared camera $2 \mathrm{~h}$ after the successful initiation of the VOI-R1.
\end{abstract}

Keywords: Venus, Atmosphere, Meteorology, Exploration, AKATSUKI

\section{Introduction}

Venus is our nearest neighboring planet with a size very similar to that of the Earth. It has been explored by the USSR, the USA, and Europe since the 1970s. The USSR VENERA series probes (Moroz 1981) landed on the surface of Venus and revealed that the temperature at the surface is $740 \mathrm{~K}$ and the pressure is 92 bars, which

\footnotetext{
*Correspondence: nakamura.masato@jaxa.jp

${ }^{1}$ Institute of Space and Astronautical Science, Japan Aerospace Exploration Agency, 3-1-1 Yoshinodai, Chuo-ku, Sagamihara, Kanagawa 252-5210, Japan

Full list of author information is available at the end of the article
}

is quite different from our terrestrial environment (Colin 1983). The atmosphere consists mainly of $\mathrm{CO}_{2}$. A striking finding is that the atmosphere rotates westward around the planet with a period of $4 \mathrm{~d}$ at an altitude of $50-60 \mathrm{~km}$, while the planet itself rotates westward more slowly with a period of 243 days; this is called superrotation (Schubert 1983). The USA's Pioneer Venus orbiter studied Venus over 12 years by remote sensing techniques (Lellouch et al. 1997; Taylor et al. 1997). Moreover, the Venusian atmosphere was studied during the Venus Express mission of the European Space Agency (Svedhem et al. 2007), which had an operational period ranging from 2006 to 2014. This mission was a modified version of the 
Mars Express mission (Chicarro et al. 2004) that was dedicated to investigations of the Martian atmosphere solely by the use of spectroscopic techniques. Venus Express also employed several spectroscopic instruments.

AKATSUKI was also designed to study the Venusian atmosphere, but in contrast to the Venus Express strategy, five cameras with narrowband filters will image Venus at different wavelengths to track the distributions of clouds and minor gaseous constituents at different heights (Fig. 1). In other words, we aim to study the Venusian atmospheric dynamics in three dimensions, while Venus Express collected mainly spectroscopic

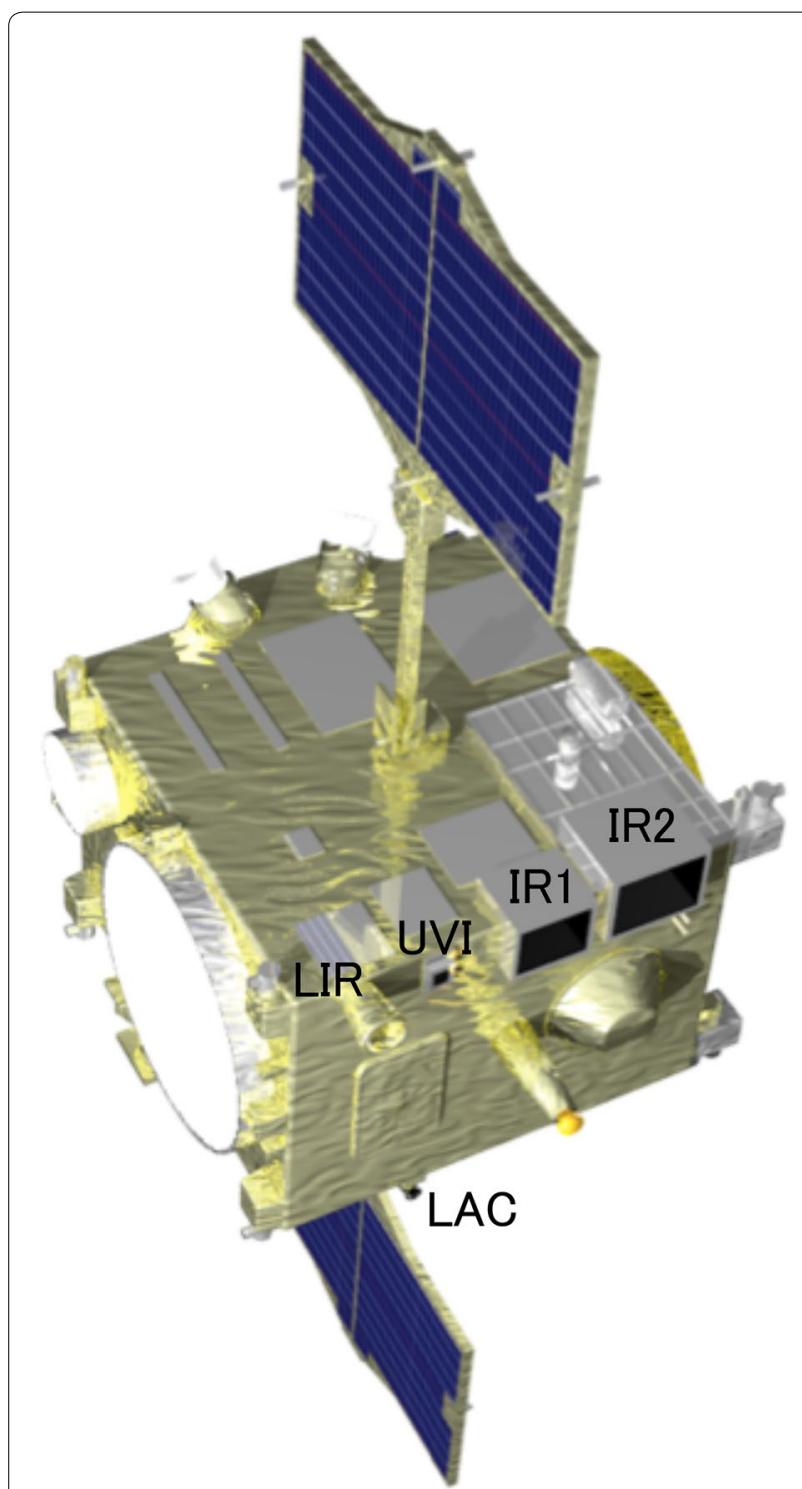

Fig. 1 View of AKATSUKI. The five photometric sensors employed as mission instruments included a 1- $\mu \mathrm{m}$ infrared camera (IR1), 2- $-\mu \mathrm{m}$ infrared camera (IR2), ultraviolet imager (UVI), long-wave infrared camera (LIR), and lightning and airglow camera (LAC) observations of the atmosphere. These two spacecraft are capable of revealing complementary aspects of the Venusian atmosphere. On Venus Express, the Venus monitoring camera (VMC) (Markiewicz et al. 2007) with four narrowband filters from ultraviolet (UV) to near infrared (IR) made similar observations, but as Venus Express was in a polar orbit, it could not track the cloud patterns appearing on Venus. AKATSUKI is on a westward equatorial orbit and is capable of taking successive images in the low- and midlatitudes of Venus, which is advantageous for studies of the atmosphere.

AKATSUKI has started collecting observations, and the first images of Venus taken by the onboard 1- $\mu \mathrm{m}$ infrared camera (IR1), ultraviolet imager (UVI), and long-wave infrared camera (LIR) are presented in "First images of Venus by the cameras" section. The scientific background for this research and data processing procedures are described in detail by Nakamura et al. $(2011,2014)$.

\section{Methods}

The development of the Japanese Venus Climate Orbiter AKATSUKI was first proposed to the Institute of Space and Astronautical Science (ISAS) in 2001, and this initiative was strongly supported by the international Venus science community as an interplanetary mission (Nakamura et al. 2007, 2011). The main goal of AKATSUKI is to shed light on the mechanism driving the fast atmospheric circulation of Venus. The systematic imaging sequencing capability of AKATSUKI is advantageous for detecting meteorological phenomena on various temporal and spatial scales. AKATSUKI has following five photometric sensors as mission instruments for imaging (Fig. 1): IR1, a 2- $\mu \mathrm{m}$ infrared camera (IR2), UVI, LIR, and a lightning and airglow camera (LAC). Except for the LIR, these photometers have changeable filters in the optics to allow for imaging at different wavelengths. AKATSUKI's long, elliptical orbit around Venus is suitable for obtaining cloud-tracked wind vectors continuously in the lowand midlatitudes. With these instruments, we expect to be able to characterize the meridional circulation, midlatitude jets, and their various wave activities.

IR1 is designed to monitor the dayside of Venus at $0.90 \mu \mathrm{m}$ and the nightside at $0.90,0.97$ and $1.01 \mu \mathrm{m}$, which are located in atmospheric windows (Iwagami et al. 2011). The measurements at 0.90 and $1.01 \mu \mathrm{m}$ will yield information about the surface material (Baines et al. 2000; Hashimoto and Sugita 2003; Hashimoto et al. 2008). IR2 utilizes atmospheric windows at wavelengths of 1.73, 2.26 and $2.32 \mu \mathrm{m}$ (Satoh et al. 2015). With these wavelengths, IR2 is most sensitive to thermal radiation originating from altitudes of $35-50 \mathrm{~km}$. IR2 also employs two more wavelengths, namely one at $2.02 \mu \mathrm{m}$ to detect variations of cloud top altitudes as intensity variations of 
reflected sunlight (Satoh et al. 2015) and an astronomical H-band centered at $1.65 \mu \mathrm{m}$. The UVI is designed to measure ultraviolet radiation scattered from the cloud top altitudes in two bands centered at 283 and $365 \mathrm{~nm}$ (Nakamura et al. 2011). The LIR detects thermal radiation emitted from the cloud tops over a rather wide wavelength region of $8-12 \mu \mathrm{m}$, and this enables mapping of the cloud top temperatures (Taguchi et al. 2007; Fukuhara et al. 2011). Unlike other imagers onboard AKATSUKI, LIR takes images of both the dayside and nightside equally. The corresponding cloud top temperature maps will reflect the cloud height distributions, whose detailed structures are unknown except for in the northern high latitudes at areas observed by Pioneer Venus (Taylor et al. 1980). The map data will also reflect the atmospheric temperature distribution. LAC is a high-speed imaging sensor that measures lightning flashes and airglow emissions on the nightside of Venus (Takahashi et al. 2008). In addition to the photometric observations mentioned above, radio occultation experiments obtain vertical profiles of the temperature, sulfuric acid density, and ionospheric electron density with high resolution (Imamura et al. 2011). For this particular experiment, the spacecraft has been equipped with an ultra-stable oscillator, which is identical to the one on Venus Express; thus, comparisons of the results from the two spacecraft are possible.

\section{Orbit}

The Japan Aerospace Exploration Agency (JAXA) successfully launched AKATSUKI at 06:58:22 (JST) on May 21, 2010, with the H-IIA F17 launch vehicle. After the successful cruise from Earth to Venus, which took about half a year, the propulsion system malfunctioned during the Venus orbit insertion (VOI) maneuver on December 7, 2010 (Nakamura et al. 2011; Hirose et al. 2012). The orbital maneuvering engine (OME) was shut down at 158 s during VOI, while 12 min of operation had been planned. Consequently, the spacecraft did not enter Venus's orbit; instead, it entered an orbit around the Sun with a period of 203 days.

The cause of the malfunction was determined to be an obstruction of the fuel-side check valve, which restricted the passage of fuel into the OME, and hence, the ratio of oxidizer to fuel gradually increased. Eventually, the combustion temperature became too high to operate the OME. The obstruction turned out to be a solid salt that was generated in the check valve during the mixing of fuel and oxidizer vapors along with helium gas, which was needed for pressurization. The vapor of the oxidizer reached the fuel-side check valve because it was able to penetrate through the seal material (polymer) of the valves. At the design phase of the spacecraft, four valves were intentionally installed to avoid the migration of vapor and the potential for unexpected explosions in the pressurized gas line. However, the possibility of vapor transmission through the seal material also should have been carefully considered.

The OME was ultimately found to be broken and unusable, but most of the fuel still remained. Thus, a decision was made to use the reaction control system (RCS) for orbital maneuvers in November 2011, which were successfully executed so that AKATSUKI would re-encounter Venus in 2015.

After the orbital maneuvers in November 2011, the orbital period became 199 days and the encounter with Venus was set for November 22, 2015. This specific date was originally chosen to achieve the shortest encounter time given the spacecraft's now limited expected lifetime. However, a detailed trajectory analysis revealed that the orbit around Venus after insertion on November 22, 2015, would be unstable. Therefore, to achieve a more stable orbit, another orbital maneuver was performed in July 2015 to set the spacecraft on a trajectory to meet Venus on December 7, 2015.

Figure 2 shows the trajectory of AKATSUKI in relation to the orbits of Venus and Earth. After December 1, 2015, the spacecraft's orbit was just outside of Venus's orbit and the velocity of the spacecraft relative to the Sun was less than that of Venus, which allowed Venus to catch up to the spacecraft from the back end. On December 7, 2015, the spacecraft approached the planet from outside of Venus's orbit and VOI-Revenge 1 (R1) procedure was implemented by using four 23 Newton class thrusters of the RCS.

Figure 3 shows the observed two-way Doppler residuals at the Usuda Deep Space Center 64-m antenna with no-burn trajectory. VOI-R1 burn (1228 s) was successfully achieved from 23:51:29 on December 6 through 00:11:57 on December 7 (UTC, onboard time). On the ground, the burn was observed at an 8-min 19-s delay (radio wave travel time between Venus and the Earth on December 7, 2015). Each colored line shows the case when the injection was interrupted at a certain percentage of the burn duration (e.g., "015" indicates $15 \%$ of the burn duration). This graph shows that, even if the burn was interrupted, the inclination of the Doppler residuals did not become flat because of the spacecraft's velocity changes caused by Venus. During the burn, the time-series variation of the Doppler residuals provided unique information and was monitored very carefully with the telemetry data sent from the spacecraft.

AKATSUKI is the first Japanese satellite to orbit a planet. After the VOI-R1, the apoapsis altitude was $\sim 440,000 \mathrm{~km}$ with an inclination of $3^{\circ}$ and orbital period of 13 days and $14 \mathrm{~h}$. Figure 4 shows the VOI-R1 geometry depicted with the Venus center coordinate. For the dual purposes of decreasing the apoapsis altitude and avoiding a long eclipse during the orbit, a trim maneuver was 


\section{VOI-R1 Geometry (Sun center)}

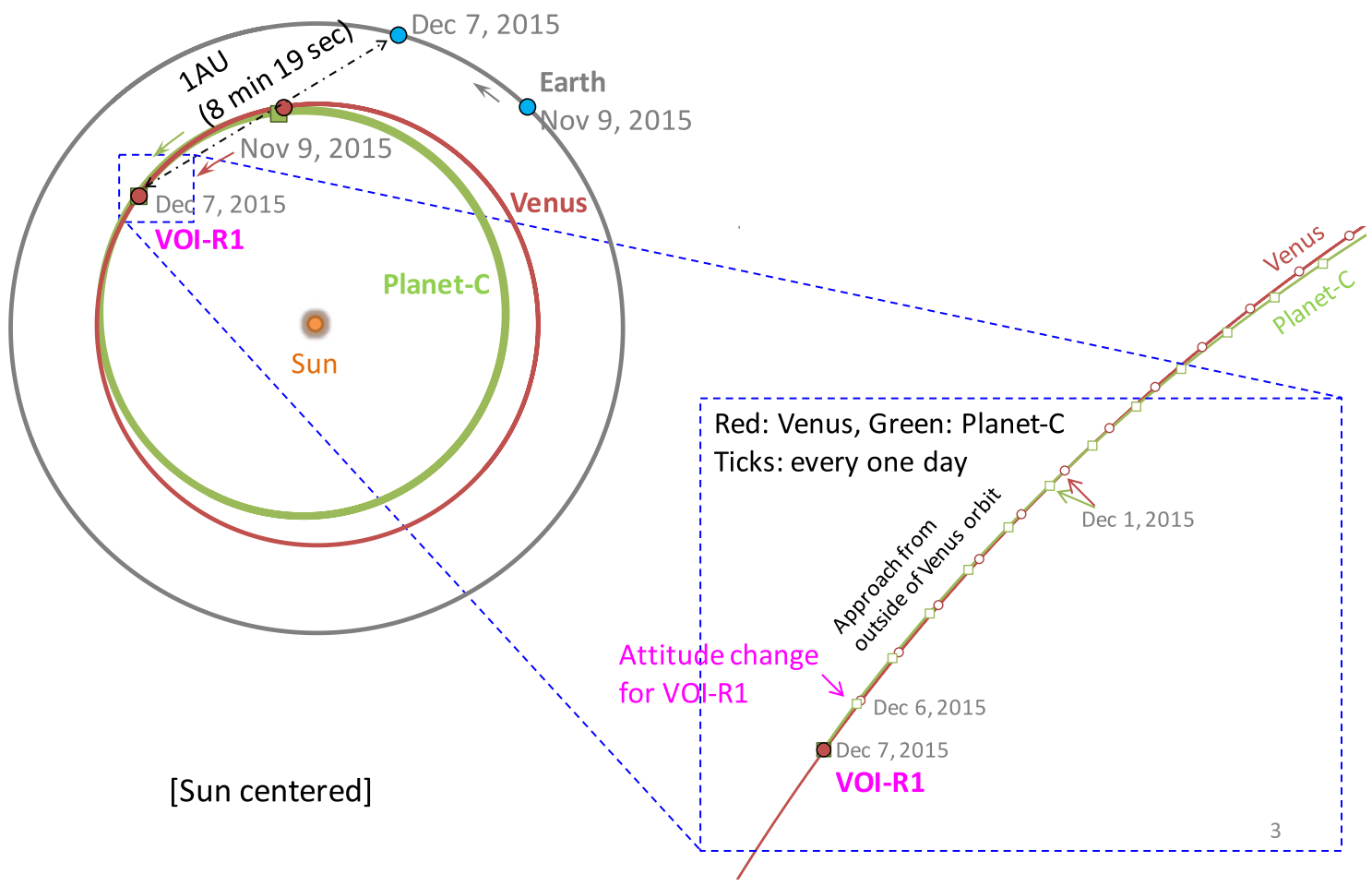

Fig. 2 VOI-R1 geometry with the Sun center coordinate. The orbits of AKATSUKI, Venus, and Earth are shown by green, red, and gray lines, respectively

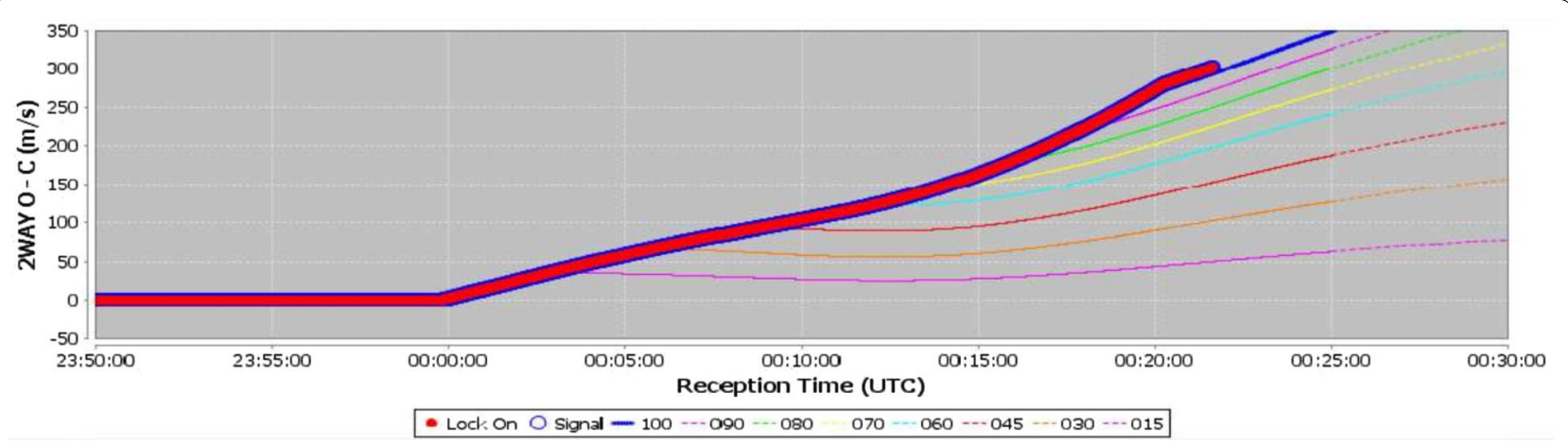

Fig. 3 Two-way Doppler residuals observed by the Usuda Deep Space Center 64-m antenna at VOI-R1 (thick red line) with some expected curves (colored thin lines). Each thin curve shows the case when the injection was interrupted at a certain percentage of the burn duration. For example, "015" indicates $15 \%$ of the burn duration

performed at the first periapsis. The apoapsis altitude is now $\sim 360,000 \mathrm{~km}$ with a periapsis altitude of 1000 $8000 \mathrm{~km}$, and the period is 10 days and $12 \mathrm{~h}$.

\section{New observation plan}

To understand the atmospheric dynamics and cloud physics of Venus, onboard science instruments are used to sense multiple height levels of the atmosphere, which enables visualization of the three-dimensional structure and dynamics. Although the new orbit around Venus is much more elongated than the original plan, the science goals and the observation strategy are basically unchanged from the original ones (Nakamura et al. 2011). The spatial resolution to be achieved around the apoapsis was degraded by a factor of 5-6 ("Global imaging" section), which had an influence on the quality of cloud 


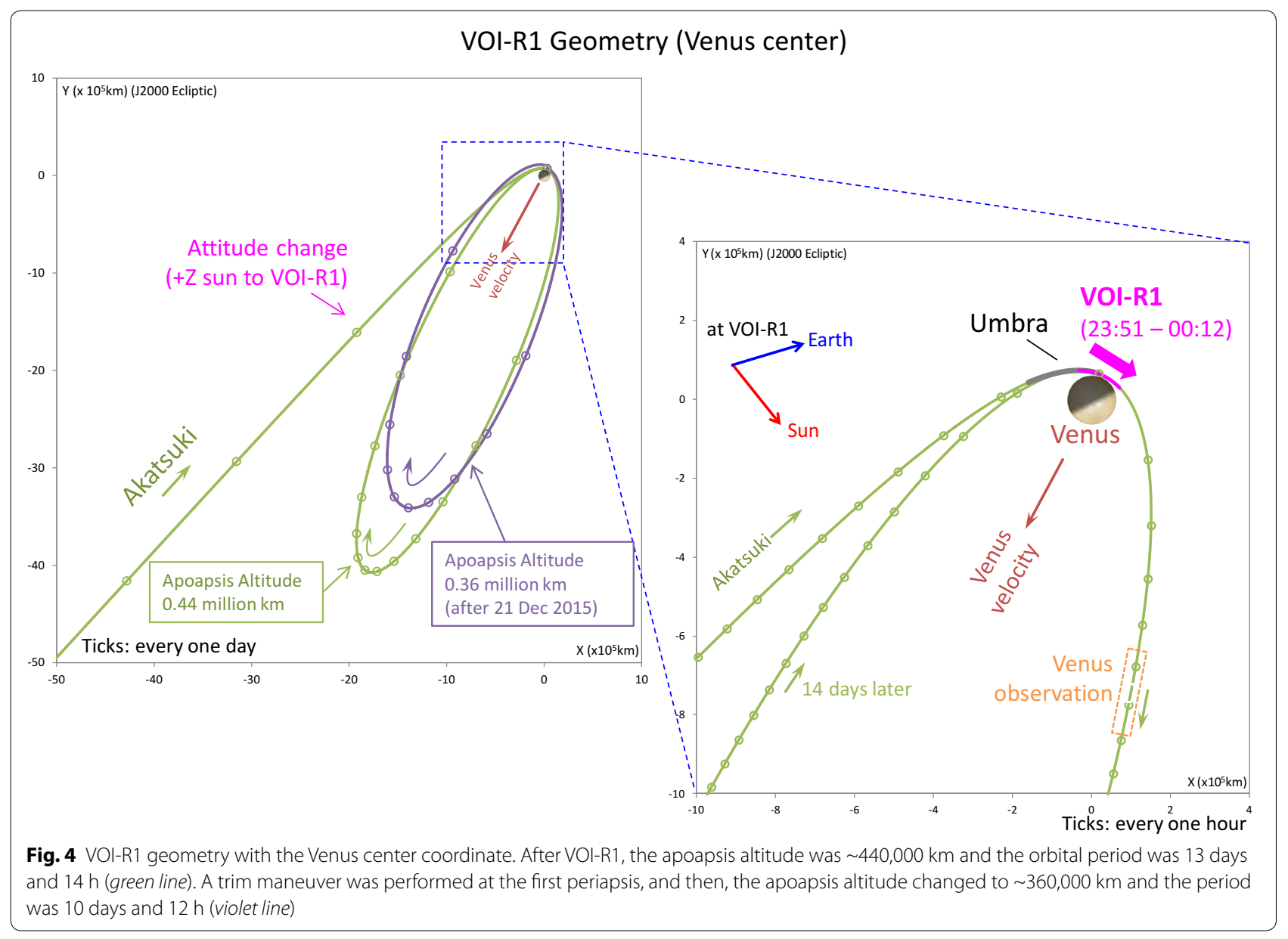

tracking measurements. However, planetary-scale winds are still expected to be retrievable from such images, and high-resolution images obtained at close distances can be used to complement them. Although the frequencies of LAC operations and radio occultation observations became much lower, the lightening observations by LAC are still very unique, and the scientific value of radio occultation observation can be maximized by coordination with the imaging observations. The observation modes are roughly classified into the groups described below in the following four subsections; these observations are conducted sequentially in each orbital revolution (Fig. 5).

\section{Global imaging}

Global imaging observations are conducted by using the IR1, IR2, UVI, and LIR in the portion of the orbit where the typical camera field of view (FOV) of $12^{\circ}$ exceeds the apparent Venus disk; this condition is satisfied over $96 \%$ of the time in one orbital revolution except for in the near periapsis region. From this portion of the orbit, cloud images will be obtained every $1-2 \mathrm{~h}$ for each observation wavelength. The pixel resolution at the Venusian surface from the apoapsis altitude of $\sim 360,000 \mathrm{~km}$ is $74 \mathrm{~km}$ for UVI, IR1, and IR2 and $300 \mathrm{~km}$ for LIR, while it is $12 \mathrm{~km}$ for UVI, IR1, and IR2 and $50 \mathrm{~km}$ for LIR from the altitude of 58,000 km where the apparent Venus disk fits into the FOV of $12^{\circ}$. Because the orbital period in the original plan would have allowed observations of the full global disk only during $60 \%$ of each orbit (Nakamura et al. 2011), the new orbit enables more continuous global monitoring. Another merit of the new orbit is that the observation geometry is stable over several days at the expense of the lower spatial resolution on average. By using the obtained global images, development of the atmospheric structure can be monitored, and wind vectors can be derived by tracking small-scale cloud features (Kouyama et al. 2012, 2013; Ogohara et al. 2012a, b; Ikegawa and Horinouchi 2016). This continuous and long-term monitoring of Venus will also provide unprecedented life cycle details of the most prominent cloud structure of Venus, the dark Y-feature, which has been interpreted to be a planetary wave that may explain the zonal wind variability and provide key hints about the nature of the mysterious 


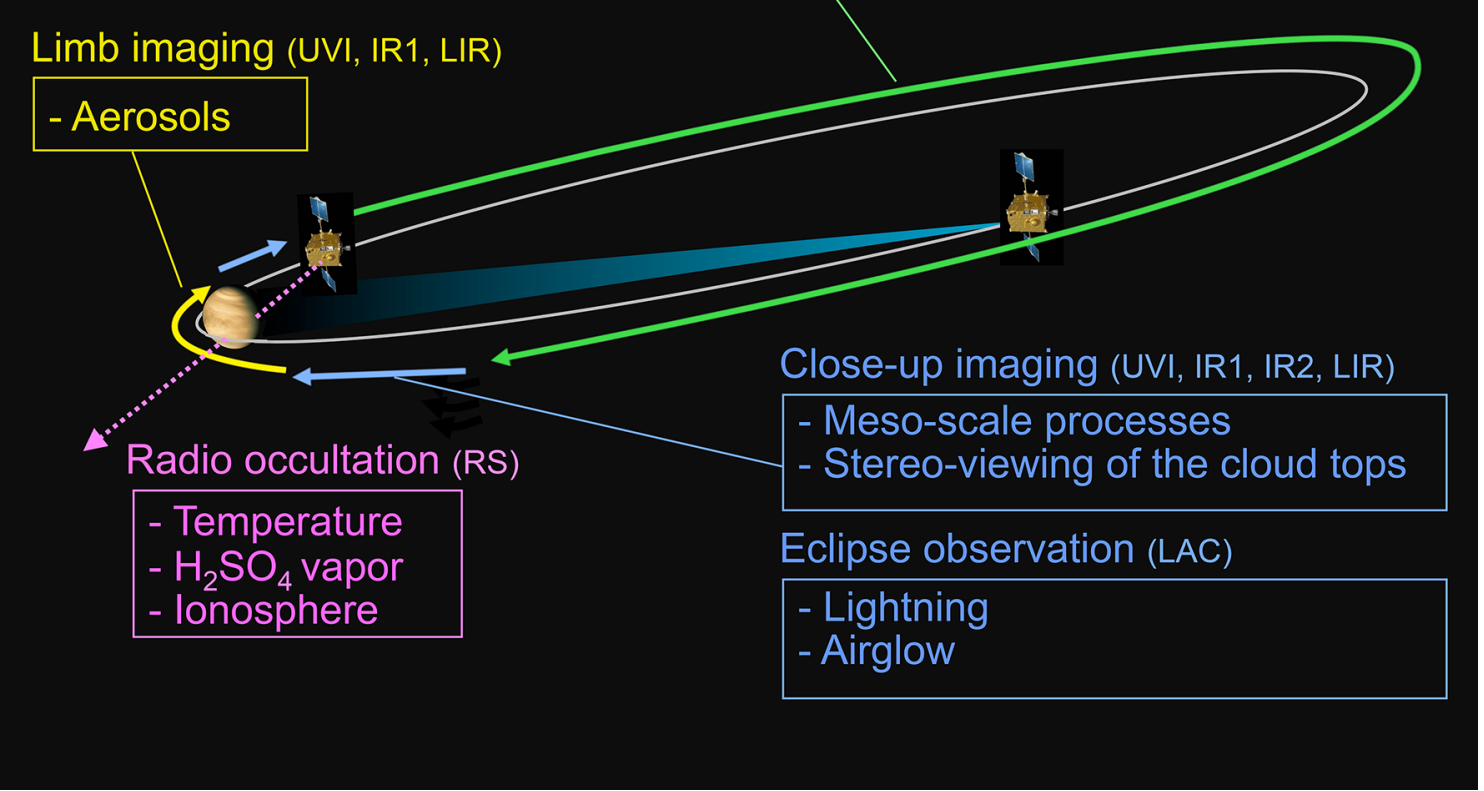

Fig. 5 Schematic view of the observation sequence along the orbit

UV absorber (Peralta et al. 2015). Monitoring of surface features on the nightside by IR1, including searches for active volcanism (Hashimoto and Imamura 2001), is also conducted primarily in this observation mode.

The camera pointing direction for this type of observation is not always nadir, but it can be shifted to the sunlit side for dayside imaging and to the dark side for nightside imaging. The purposes of this angular offset are (1) to include the planetary limb in the image so that the pointing direction can be determined accurately from the limb position, (2) to maximize the area of the atmosphere or the surface observable with each filter, and (3) to avoid stray light when observing the nightside.

\section{Close-up imaging}

In this observation mode, a particular point on the cloud layer is continuously monitored by using the UVI, IR1, IR2, and LIR from distances shorter than $\sim 50,000 \mathrm{~km}$ for the purpose of observing the temporal development of mesoscale processes and also for stereo-viewing of the cloud tops. The pixel resolution at the Venusian surface is $0.2-1.6 \mathrm{~km}$ for UVI, IR1, and IR2 and $0.9-7.0 \mathrm{~km}$ for LIR from the periapsis altitude of $1000-8000 \mathrm{~km}$. During this observation sequence, the spacecraft attitude is controlled so that the camera FOV continuously captures roughly the same region of the cloud tops.

\section{Limb imaging}

The vertical distribution of aerosols that extend up to $\sim 100 \mathrm{~km}$ altitude is observed with the limb-viewing geometry around the dayside periapsis passages by using UVI, IR1 $(0.90 \mu \mathrm{m})$, and LIR. The layered distribution of aerosols seen in the limb images taken by the Galileo solid-state imager (SSI) (Belton et al. 1991) and Venus Express VMC (Titov et al. 2012) suggests that unknown chemical/dynamical processes are at work in aerosol formation; extensive observations covering wider regions with multiple wavelengths should provide clues to the mechanism. When the periapsis altitude is $1000 \mathrm{~km}$, the minimum distance to the tangential point is $3500 \mathrm{~km}$, and this gives a vertical resolution of $0.7 \mathrm{~km}$ for UVI and IR1 and $3 \mathrm{~km}$ for LIR.

\section{Eclipse observations}

The eclipse (umbra) region along the orbit is allocated to lightning observations by LAC. Eclipses occur mostly 
near the periapsis with a typical duration of $30 \mathrm{~min}$. LAC is operated in nadir-pointing geometry and waits for lightning flashes to collect data with an event trigger method. LAC can also observe night airglows by continuously recording the brightness along swaths scanned by the attitude maneuver or the orbital motion of the spacecraft.

\section{Radio occultation}

Radio occultation experiments (RS) that use an ultra-stable oscillator (USO) are performed when the spacecraft is hidden by Venus as viewed from the tracking station (Imamura et al. 2011). Venus Express radio occultation has revealed vertical temperature profiles at various locations and local times (Tellmann et al. 2009); one merit of the AKATSUKI's observation system is that the location probed by RS can be observed by the cameras a short time before the ingress or short time after the egress because of the equatorial orbit, thus enabling quasisimultaneous observations. Since the dense Venusian atmosphere causes considerable ray bending exceeding several tens of degrees, spacecraft steering is required to compensate for this effect while the occultation geometry changes from ingress occultation to egress occultation.

\section{First images of Venus by the cameras}

AKATSUKI took images of Venus immediately after the VOI-R1 with the following three instruments: IR1, UVI, and LIR. The other two instruments (IR2 and LAC) were not operated at this time because their functions had not been checked before the VOI-R1. The first images of Venus were taken at the positions of $\sim 67,000 \mathrm{~km}$ for IR1 and $\sim 72,000 \mathrm{~km}$ for UVI and LIR, far from the Venus disk. The solar phase angle at the sub-observer point was $\sim 45^{\circ}$ with the evening terminator in view (Fig. 4). Figure $6 a-c$ shows the images taken by IR1, UVI, and LIR, respectively, and Table 1 presents a summary of the observations. No data reduction procedures have been performed for the images except for several onboard processing steps (i.e., median filtering and subtraction of the dark current for IR1 and UVI, desmearing for UVI, and accumulation of 32 images and subtraction of a shutter image for LIR).

The IR1 image shows the $0.90-\mu \mathrm{m}$ solar radiation scattered by the upper clouds (Iwagami et al. 2011). This channel is centered on the continuum. Although the area near the eastern limb was not visible because of the limited operation of the discrete attitude control (in spite of the quick orbital motion of AKATSUKI), it was confirmed that Venus has a faint appearance over the entire disk in this channel. Belton et al. (1991) showed from the $0.986-\mu \mathrm{m}$ images obtained by the Galileo SSI that Venus has a contrast of $3 \%$ after the removal of terminator and limb brightness gradients. The contrast sources for the IR1 images, together with those for the IR2 and LIR images, are discussed in Takagi and Iwagami (2011). The continuous IR1 images with such contrast will be used to sound horizontal cloud-tracked velocities near the base of the upper clouds (58-64 km) (e.g., Peralta et al. 2007; Sánchez-Lavega et al. 2008).

The UVI image at a wavelength of $283 \mathrm{~nm}$ reflects the spatial distribution of $\mathrm{SO}_{2}$, which attenuates solar radiation scattered by clouds at cloud level, and that of the upper haze, which enhances scattering. This is the first time a snapshot of Venus has been captured at this wavelength. Relatively bright cell-like structures exist in the low latitudes. Dark and bright streaky structures, which form part of the bow shape, become prominent in the midlatitudes. Bright polar bands are also clearly seen in the high latitudes. Although this channel is outside of the band of the unknown UV absorber, which was measured by previous spacecraft (Pioneer Venus, Galileo, and Venus Express), the morphology at $283 \mathrm{~nm}$ was found to be similar to those seen in previous UV images. Together with the other UVI image at a wavelength of $365 \mathrm{~nm}$, the continuous UVI images will be used to derive horizontal

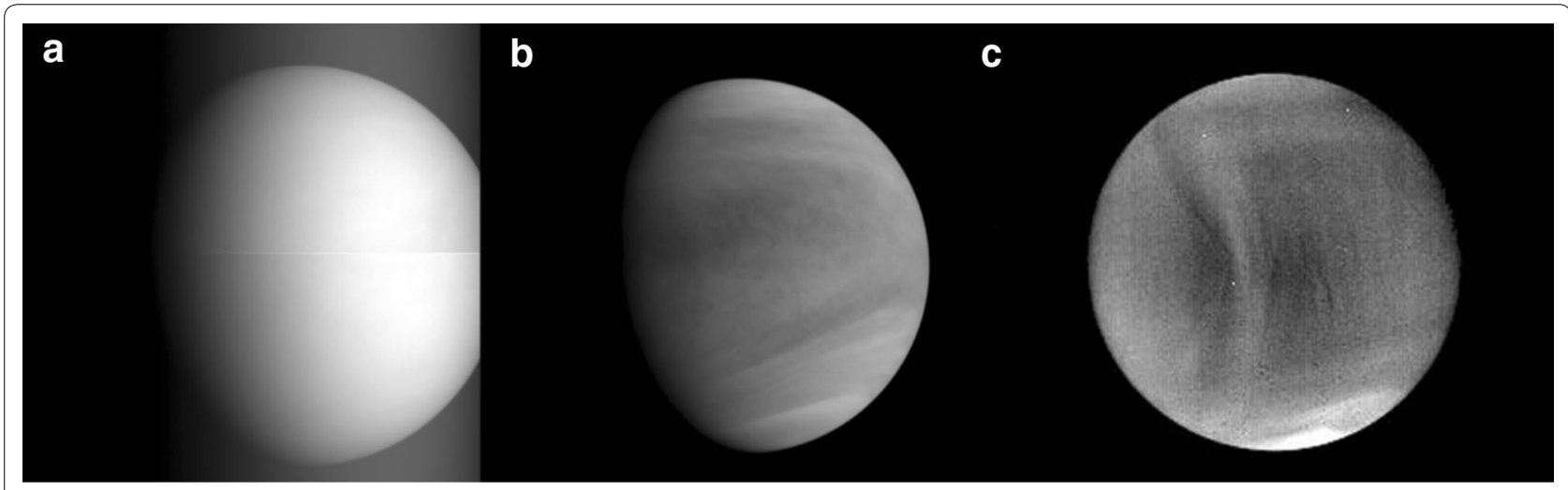

Fig. 6 First memorial images taken by the a IR1, b UVI, and $\mathbf{c} L I R$ on "the AKATSUKI satellite" of Venus 
Table 1 Summary of the Venus observations taken immediately after the VOI-R1 operation

\begin{tabular}{|c|c|c|c|}
\hline & IR1 & UVI & LIR \\
\hline $\begin{array}{l}\text { Observation date } \\
\text { Observation time (UT) }\end{array}$ & $\begin{array}{l}\text { December 7, } 2015 \\
\text { 4:51:56 }\end{array}$ & $\begin{array}{l}\text { December 7, } 2015 \\
\text { 5:19:53 }\end{array}$ & $\begin{array}{l}\text { December 7, } 2015 \\
\text { 5:26:02 }\end{array}$ \\
\hline Wavelength & $0.90 \mu \mathrm{m}^{\mathrm{a}}$ & $283 \mathrm{~nm}$ & $10 \mu \mathrm{m}$ \\
\hline Exposure time (s) & 3.0 & 0.25 & $34^{\mathrm{b}}$ \\
\hline Distance between AKATSUKI and Venus $(\mathrm{km})$ & $6.8 \times 10^{4}$ & $7.2 \times 10^{4}$ & $7.3 \times 10^{4}$ \\
\hline Apparent diameter $\left(^{\circ}\right)^{C}$ & 10.4 & 9.7 & 9.6 \\
\hline Spatial resolution (km/pixel) ${ }^{d}$ & 14.2 & 15.1 & 63.9 \\
\hline \multicolumn{4}{|l|}{ Sub-observer point } \\
\hline Latitude $\left(^{\circ}\right)$ & -6.7 & -6.6 & -6.6 \\
\hline Longitude $\left(^{\circ}\right)$ & 96.4 & 95.1 & 94.9 \\
\hline Solar phase angle $\left({ }^{\circ}\right)$ & 45.0 & 46.3 & 46.6 \\
\hline \multicolumn{4}{|l|}{ Subsolar point } \\
\hline Latitude $\left(^{\circ}\right)$ & -2.6 & -2.6 & -2.6 \\
\hline Longitude $\left(^{\circ}\right)$ & 141.4 & 141.5 & 141.5 \\
\hline Solar phase angle $\left(^{\circ}\right)$ & 48.9 & 50.0 & 50.2 \\
\hline
\end{tabular}

a The filter for dayside imaging was used

b The composite image was made by superimposing 32 images. Exposure time for an image was $1.1 \mathrm{~s}$

c A tangent height assumed to be $70 \mathrm{~km}$ from the surface was added to the radius of Venus $(6051.8 \mathrm{~km})$

d Spatial resolution was calculated with the pixel scale of $0.012(\%$ pixel) for IR1 and UVI and $0.05(\%$ pixel) for LIR

cloud-tracked velocities near the cloud top altitudes of 62-70 km (e.g., Kouyama et al. 2012, 2013; Ogohara et al. 2012a, b; Ikegawa and Horinouchi 2016). The spatial resolution of the IR1 and UVI images shown in Fig. 6a, b is $\sim 15 \mathrm{~km} /$ pixel, which is three or four times better than that $(\sim 50 \mathrm{~km} /$ pixel) of the images obtained by the Venus Express VMC near the apocenter (Titov et al. 2012). Comparisons between the time series of the images at the two channels (283 and $365 \mathrm{~nm}$ ) will also shed light on their relationship with the cloud top structure. The solar phase angle dependence of aerosol scattering and darkbright contrasts will be used to develop an aerosol model and determine the vertical distribution of UV absorbers, $\mathrm{SO}_{2}$, and the unknown UV absorber (Lee et al. 2015; Petrova et al. 2015; Satoh et al. 2015). This aerosol model will be taken into account in albedo calculations, and the optical depth of the UV absorbers can be estimated in a similar manner to method used by Molaverdikhani et al. (2012). Ground-based observations will also be useful for evaluating the gaseous $\mathrm{SO}_{2}$ distribution over the planet; an example can be found in Encrenaz et al. (2013).

The LIR image shows the thermal radiation emitted from the cloud top altitudes with a single band-pass filter of 8-12 $\mu \mathrm{m}$ (Taguchi et al. 2007; Fukuhara et al. 2011). This is a composite image that was made by superimposing 32 raw images to improve the signal-to-noise ratio. A shutter image was subtracted from the Venus image to correct a pixel-to-pixel variation in offset. No correction for thermal radiation from the LIR itself was performed.
The spatial resolution of the LIR image is $\sim 60 \mathrm{~km} /$ pixel, which is the highest spatial resolution image of Venus ever obtained in the mid-infrared wavelengths. The southern polar region is the brightest (highest in temperature) region, which corresponds to the polar dipole. Even after considering that the sub-observer latitude is at $\sim 7^{\circ} \mathrm{S}$, it is apparent that north-south asymmetry in the brightness of the polar regions exists. The streaky structures seen in the UVI image are also visible in the midlatitudes. Of particular interest is the bright bow-like structure extending toward high latitudes near the evening terminator, which was not seen in the previous LIR images captured just after the VOI failure in December 2010 (Taguchi et al. 2012). Such a bow-like structure is also evident in the ground-based mid-infrared images, but it appeared as a dark feature (Sato et al. 2014). Continuous monitoring of the cloud top morphology will provide clues for understanding what mechanism causes such an interesting feature.

\section{Concluding remarks}

In 2010, Japan's first trial to put the spacecraft AKATSUKI into orbit around Venus was unsuccessful. Since that time, ISAS has investigated the cause of the malfunction during the first orbit insertion and made a second challenging attempt at Venus orbit insertion in 2015 with the injured spacecraft. The second orbit insertion was executed flawlessly, and AKATSUKI will be able to achieve all science objectives in the new science orbit. All 
AKATSUKI instruments are working well, and the first images have already provided new and intriguing observations of Venus. AKATSUKI will continue to send data for two or more years, and planetary exploration by Japan will enter a new era when AKATSUKI continuously delivers data to the world on the changing planet.

\section{Abbreviations}

FOV: field of view; IR1: 1- $\mu$ m infrared camera; IR2: 2- $\mu$ m infrared camera; ISAS: Institute of Space and Astronautical Science; JAXA: Japan Aerospace Exploration Agency; LAC: lightning and airglow camera; LIR: long-wave infrared camera; OME: orbital maneuver engine; RCS: reaction control system; RS: radio occultation experiments; SSI: solid-state imager; UVI: ultraviolet imager; VMC: Venus monitoring camera; VOI:Venus orbit insertion on December 7, 2010; VOI-R1: Venus orbit insertion-revenge 1.

\section{Authors' contributions}

For the AKATSUKI project of ISAS/JAXA, NM was the project manager, IT was the project scientist, and IN was the project engineer. $K Y, H C, N J$, IT, IK, TT, $\mathrm{TH}, \mathrm{TS}, \mathrm{NS}, \mathrm{HT}, \mathrm{HA}$, and $\mathrm{KY}$ were core members of the engineering team. AT, ST, SM, UM, YA, IN, WS, TM, FT, TY, YM, IM, OS, UK, HGL, TM, MY, OK, SN, KY, KT, HN, NR, YY, HT, YM, HY-Y, KH, SK, ST, AH, MS, STM, TS, NK, PJ, and LYJ were core members of the science team. Some members of the science team served as principal investigators (PIs) of the scientific instruments; specifically, WS, IN, ST, TM, TY, and IT were PIs for the work involving the UVI, IR1, IR2, LIR, LAC, and RS, respectively. All authors read and approved the final manuscript.

\section{Author details}

${ }^{1}$ Institute of Space and Astronautical Science, Japan Aerospace Exploration Agency, 3-1-1 Yoshinodai, Chuo-ku, Sagamihara, Kanagawa 252-5210, Japan. 2 Department of Earth and Planetary Science, University of Tokyo, Bunkyo-ku, Tokyo 113-0033, Japan. ${ }^{3}$ Space Information Center, Hokkaido Information University, 59-2 Nishi-nopporo, Ebetsu, Hokkaido 069-8585, Japan. ${ }^{4}$ Department of Physics, Rikkyo University, 3-34-1, Nishi-ikebukuro, Toshima-ku, Tokyo, 171-8501, Japan. ${ }^{5}$ National Institute of Information and Communications Technology, 4-2-1, Nukui-Kitamachi, Koganei, Tokyo 184-8795, Japan. ${ }^{6}$ Department of Cosmosciences, Hokkaido University, Kita-10 Nishi-8, Kita-ku, Sapporo, Hokkaido 060-0810, Japan. ${ }^{7}$ Planetary Exploration Research Center, Chiba Institute of Technology, 2-17-1 Tsudanuma, Narashino, Chiba 275-0016, Japan. ${ }^{8}$ School of Commerce, Senshu University, 2-1-1, Higashimita, Tama-ku, Kawasaki-shi, Kanagawa 214-8580, Japan. ${ }^{9}$ Department of Earth Sciences, Okayama University, Tsushima-Naka, Okayama 700-8530, Japan. ${ }^{10}$ Department of Physics, Kyoto Sangyo University, Motoyama, Kamigamo, Kita-ku, Kyoto 603-8555, Japan. ${ }^{11}$ Department of Astronomy and Earth Sciences, Tokyo Gakugei University, 4-1-1 Nukuikitamachi, Koganei, Tokyo 184-8501, Japan. 12 Department of Electronic Systems Engineering, The University of Shiga Prefecture, 2500, Hassaka-cho, Hikone-City, Shiga 522-8533, Japan. ${ }^{13}$ Department of Geophysics, Tohoku University, Aramaki-aoba, Aoba-ku, Sendai, Miyagi 980-8578, Japan. ${ }^{14}$ National Institute of Advanced Industrial Science and Technology, 1-1-1 Umezono, Tsukuba, Ibaraki 305-8560, Japan. ${ }^{15}$ Research Center for Advanced Information Science and Technology, Tsuruga, Ikki-machi, Aizu-Wakamatsu, Fukushima 965-8580, Japan. ${ }^{16}$ Faculty of Environmental Earth Science, Hokkaido University, Kita-10 Nishi-5, Sapporo, Hokkaido 060-0810, Japan. ${ }^{17}$ Research Institute for Applied Mechanics, Kyushu University, 6-1 Kasuga-kouen, Kasuga, Fukuoka 816-8580, Japan. ${ }^{18}$ Department of Planetology, Kobe University, 1-1 Rokkodai-cho, Nada-ku, Kobe, Hyogo 657-8501, Japan. ${ }^{19}$ Japan Agency for Marine-Earth Science and Technology, 3173-25, Showa-machi, Kanazawa-ku, Yokohama-city, Kanagawa 236-0001, Japan. ${ }^{20}$ Research and Information Center, Tokai University, 4-1-1 Kitakaname, Hiratsuka, Kanagawa 259-1292, Japan. ${ }^{21}$ Department of Earth and Planetary Sciences, Kyushu University, 744 Motooka, Nishi-ku, Fukuoka 819-0395, Japan.

\section{Acknowledgements}

We gratefully thank NEC corporation, Fujitsu Limited, Sumitomo Heavy Industries, Ltd., Nikon Corporation, Mitsubishi Heavy Industries, Ltd., IHI AEROSPACE Co., Ltd., Meisei Electric Co., Ltd., Mitsubishi Electric Corporation, Hamamatsu Photonics K.K., NEC Space Technologies, Ltd., Space Engineering Development
Co., Ltd., FUJITOK Corporation, K. K. MAGOSHI, and TimeTech GmbH for their contribution to the design, manufacturing, and operation of AKATSUKI since 2001.

\section{Competing interests}

The authors declare that they have no competing interests.

Received: 5 January 2016 Accepted: 29 April 2016

Published online: 06 May 2016

\section{References}

Baines KH et al (2000) Detection of sub-micron radiation from the surface of Venus by Cassini/VIMS. Icarus 148:307-311

Belton MJS et al (1991) Imaging from Galileo of the Venus cloud deck. Science 253:1531-1536

Chicarro A, Martin P, Traunter R (2004) The Mars Express mission: an overview. In: Wilson A (ed) Mars Express. European Space Agency Publication Division, Noordwijk, pp 3-16

Colin L (1983) Basic facts about Venus. In: Hunten DM, Colin L, Donahue TM, Morozet VI (eds) Venus. University of Arizona Press, Tucson, pp 10-26

Encrenaz T, Greathouse TK, Richter MJ, Lacy J, Widemann T, Bézard B, Fouchet T, deWitt C, Atreya SK (2013) HDO and SO thermal mapping on Venus. II. The $\mathrm{SO}_{2}$ spatial distribution above and within the clouds. Astron Astrophys 559:A65. doi:10.1051/0004-6361/201322264

Fukuhara T, Taguchi M, Imamura T, Nakamura M, Ueno M, Suzuki M, Iwagami N, Sato M, Mitsuyama K, Hashimoto GL, Ohshima R, Kouyama T, Ando H, Futaguchi M (2011) LIR: longwave infrared camera onboard the Venus orbiter Akatsuki. Earth Planets Space 63:1009-1018

Hashimoto GL, Imamura T (2001) Elucidating the rate of volcanism on Venus: detection of lava eruptions using near-infrared observations. Icarus 154:239-243

Hashimoto GL, Sugita S (2003) On observing the compositional variability of the surface of Venus using nightside near-infrared thermal radiation. J Geophys Res 108:5109. doi:10.1029/2003JE002082

Hashimoto GL, Roos-Serote M, Sugita S, Gilmore MS, Kamp LW, Carlson RW Baines KH (2008) Felsic highland crust on Venus suggested by Galileo near-infrared mapping spectrometer data. J Geophys Res 113:E00B24. doi:10.1029/2008JE003134

Hirose C, Ishii N, Kawakatsu Y, Ukai C, Terada H (2012) The trajectory control strategies for Akatsuki re-insertion into the Venus orbit. In: Proceedings of the 23rd international symposium on space flight dynamics

Ikegawa S, Horinouchi T (2016) Improved automatic estimation of winds at the cloud top of Venus using superposition of cross-correlation surfaces. Icarus 271:98-119

Imamura T, Toda T, Tomiki A, Hirahara D, Hayashiyama T, Mochizuki N, Yaamoto Z, Abe T, Iwata T, Noda H, Futaana Y, Ando H, Häusler B, Pätzold M, Nabatov A (2011) Radio occultation experiment of the Venus atmosphere and ionosphere with the Venus orbiter Akatsuki. Earth Planets Space 63:493-501

Iwagami N, Takagi S, Ohtsuki S, Ueno M, Uemizu K, Satoh T, Sakanoi T, Hashimoto GL (2011) Science requirements and description of the $1 \mu \mathrm{m}$ camera onboard the Akatsuki Venus Orbiter. Earth Planets Space 63:487-492

Kouyama T, Imamura T, Nakamura M, Satoh T, Futaana Y (2012) Horizontal structure of planetary-scale waves at the cloud top of Venus deduced from Galileo SSI images with an improved cloud-tracking technique. Planet Space Sci 60:207-216

Kouyama T, Imamura T, Nakamura M, Satoh T, Futaana Y (2013) Long-term variation in the cloud-tracked zonal velocities at the cloud top of Venus deduced from Venus Express VMC images. J Geophys Res 118:37-46. doi: 10.1029/2011JE004013

Lee YJ, Imamura T, Schröder SE, Marcq E (2015) Long-term variations of the UV contrast on Venus observed by the Venus monitoring camera on board Venus Express. Icarus 253:1-15. doi:10.1016/j.icarus.2015.02.015

Lellouch E, Clancy T, Crisp D, Kliore AJ, Titov D, Bougher SW (1997) Nearinfrared sounding of the lower atmosphere of Venus. In: Bougher SW, Hunten DM, Phillips RJ (eds) Venus II. University of Arizona Press, Tucson, pp 295-321 
Markiewicz WJ et al (2007) Venus monitoring camera for Venus Express. Planet Space Sci 55:1701-1711

Molaverdikhani K, McGouldricK K, Esposito LW (2012) The abundance and vertical distribution of the unknown ultraviolet absorber in the Venusian atmosphere from analysis of Venus Monitoring Camera images. Icarus 217:648-660

Moroz VI (1981) The atmosphere of Venus. Space Sci Rev 29:3-127

Nakamura M, Imamura T, Ueno M, Iwagami N, Satoh T, Watanabe S, Taguchi M, Takahashi Y, Suzuki M, Abe T, Hashimoto GL, Sakanoi T, Okano S, Kasaba Y, Yoshida J, Yamada M, Ishii N, Yamada T, Uemizu K, Fukuhara T, Oyama K (2007) Planet-C: Venus climate orbiter mission of Japan. Planet Space Sci 55:1831-1842

Nakamura M, Imamura T, Ishii N, Abe T, Satoh T, Suzuki M, Ueno M, Yamazaki A, Iwagami N, Watanabe S, Taguchi M, Fukuhara T, Takahashi Y, Yamada M, Hoshino N, Ohtsuki S, Uemizu K, Hashimoto GL, Takagi M, Matsuda Y, Ogohara K, Sato N, Kasaba Y, Kouyama T, Hirata N, Nakamura R, Yamamoto Y, Okada N, Horinouchi T, Yamamoto M, Hayashi Y (2011) Overview of Venus orbiter, Akatsuki. Earth Planets Space 63:443-457

Nakamura M, Kawakatsu Y, Hirose C, Imamura T, Ishii N, Abe T, Yamazaki A, Yamada M, Ogohara K, Uemizu K, Fukuhara T, Ohtsuki S, Satoh T, Suzuki M, Ueno M, Nakatsuka J, Iwagami N, Taguchi M, Watanabe S, Takahashi Y, Hashimoto GL, Yamamoto H (2014) Return to Venus of the Japanese Venus climate orbiter AKATSUKI. Acta Astronaut 93:384-389

Ogohara K, Kouyama T, Yamamoto H, Sato N, Takagi M, Imamura T (2012a) A newly developed cloud tracking system for the Venus climate orbiter Akatsuki and preliminary results using Venus Express data. Theor Appl Mech Jpn 60:195-204

Ogohara K, Kouyama T, Yamamoto H, Sato N, Takagi M, Imamura T (2012b) Automated cloud tracking system for the Akatsuki Venus climate orbiter data. Icarus 217:661-668. doi:10.1016/j.icarus.2011.05.017

Peralta J, Hueso R, Sánchez-Lavega A (2007) A reanalysis of Venus winds at two cloud levels from Galileo SSI images. Icarus 190:469-477

Peralta J, Sánchez-Lavega A, López-Valverde MA, Luz D, Machado P (2015) Venus's major cloud feature as an equatorially trapped wave distorted by the wind. Geophys Res Lett 42:705-711. doi:10.1002/2014GL062280

Petrova EV, Shalygina OS, Markiewicz WJ (2015) UV contrasts and microphysical properties of the upper clouds of Venus from the UV and NIR VMC/ VEx images. Icarus 260:190-204. doi:10.1016/j.icarus.2015.07.015

Sánchez-Lavega A et al (2008) Variable winds on Venus mapped in three dimensions. Geophys Res Lett 35:L13204. doi:10.1029/2008GL033817
Sato TM, Sagawa H, Kouyama T, Mitsuyama K, Satoh T, Ohtsuki S, Ueno M, Kasaba Y, Nakamura M, Imamura T (2014) Cloud top structure of Venus revealed by Subaru/COMICS mid-infrared images. Icarus 243:386-399

Satoh T, Ohtsuki S, Iwagami N, Ueno M, Uemizu K, Suzuki M, Hashimoto GL, Sakanoi T, Kasaba Y, Nakamura R, Imamura T, Nakamura M, Fukuhara T, Yamazaki A, Yamada M (2015) Venus' clouds inferred from the phase curves acquired by IR1 and IR2 on board Akatsuki. Icarus 248:213-220

Schubert G (1983) General circulation and dynamical state of the Venus atmosphere. In: Hunten DM, Colin L, Donahue TM, Morozet VI (eds) Venus. University of Arizona Press, Tucson, pp 681-765

Svedhem $\mathrm{H}$ et al (2007) Venus Express-the first European mission to Venus. Planet Space Sci 55:1636-1652

Taguchi M, Fukuhara T, Imamura T, Nakamura M, Iwagami N, Ueno M, Suzuki M, Hashimoto GL, Mitsuyama K (2007) Longwave infrared camera onboard the Venus climate orbiter. Adv Space Res 40:861-868

Taguchi M, Fukuhara T, Futaguchi M, Sato M, Imamura T, Mitsuyama K, Nakamura M, Ueno M, Suzuki M, Iwagami N, Hashimoto GL (2012) Characteristic features in Venus' nightside cloud-top temperature obtained by Akatsuki/LIR. Icarus 219:502-504

Takagi S, Iwagami N (2011) Contrast sources for the IR images taken by the Venus mission AKATSUKI. Earth Planets Space 63:435-442

Takahashi Y, Yoshida J, Yair Y, Imamura T, Nakamura M (2008) Lightning detection by LAC onboard the Japanese Venus climate orbiter. Planet-C Space Sci Rev 137:317-334

Taylor FW, Beer R, Chahine MT, Diner DJ, Elson LS, Haskins RD, McCleese DJ, Martonchik JV, Reichley PE (1980) Structure and meteorology of the middle atmosphere of Venus: infrared remote sensing from the Pioneer Orbiter. J Geophys Res 85:7963-8006

Taylor FW, Crisp D, Bezard B (1997) Near-infrared sounding of the lower atmosphere of Venus. In: Bougher SW, Hunten DM, Phillips RJ (eds) Venus II. University of Arizona Press, Tucson, pp 325-352

Tellmann S, Pätzold M, Häusler B, Bird BM, Tyler GL (2009) Structure of the Venus neutral atmosphere as observed by the Radio Science experiment VeRa on Venus Express. J Geophys Res 114:E00B36. doi:10.1029/20 08JE003204

Titov DV et al (2012) Morphology of the cloud tops as observed by the Venus Express monitoring camera. Icarus 217:682-701

\section{Submit your manuscript to a SpringerOpen ${ }^{\circ}$ journal and benefit from:}

- Convenient online submission

- Rigorous peer review

- Immediate publication on acceptance

- Open access: articles freely available online

- High visibility within the field

- Retaining the copyright to your article

Submit your next manuscript at $\boldsymbol{\nabla}$ springeropen.com 